\title{
Modifying Root Structure of Cultivated Muskmelon to Improve Vine Decline Resistance
}

\author{
Rita de C.S. Dias, Belén Picó, Javier Herraiz, Amparo Espinós, and \\ Fernando Nuez \\ Centro de Conservación y Mejora de la Agrodiversidad Valenciana, \\ Departamento de Biotecnología (Genética), Universidad Politécnica de \\ Valencia, Camino de Vera 14, Valencia, 46020, Spain
}

Additional index words. cucurbits, Monosporascus, Acremonium, root morphology, breeding, resistance to fungi

Abstract. Vine decline is limiting muskmelon production in many growing areas. Monosporascus cannonballus Pollack and Uecker and Acremonium cucurbitacearum Alfaro-García, W. Gams, and J. García-Jiménez are the main causal agents of this disease in Spain. The wild accession Pat81 (Cucumis melo subsp. agrestis Jeffrey) has shown to be highly resistant in naturally infested fields and after artificial inoculations. In three greenhouse experiments conducted over two seasons, the root structure of Pat81 was examined and compared to the highly susceptible commercial cultivar Amarillo Canario (AC). Pat81 produced a more vigorous, branched, and longer root system, conferring to this accession a higher capacity for the uptake of water and nutrients, even after inoculation using naturally infested soil. To determine the plasticity of the root systems, the effect of five different soil substrates on root growth was assayed. The root morphology was highly influenced by the soil substrate. Differences between genotypes appeared at 10 weeks after transplanting using sand as soil substrate. An organic substrate made up of well-decomposed peat and sand minimized the genotype $x$ substrate interactions, and facilitated root analysis. This substrate allowed bringing the sampling date forward to flowering (at 7 weeks after transplanting). The maximum root length, the number and size of lateral roots (diameter $0.5-1 \mathrm{~mm}$ ) and branching order, consistently differed between the two genotypes in most of the assayed substrates. These easily measurable root traits can be used as selection criteria in healthy soils to breed a larger root system more tolerant to stress. In addition, in inoculated soils the greater root absorbent area and the reduced lesion intensity of Pat81 could have applications to increase vine decline resistance of cultivated melons. By using segregant populations derived from the cross AC $\times$ Pat81, we are trying to modify the root structure of muskmelon in order to offer a genetic alternative to the expensive strategy of grafting muskmelon varieties onto rootstocks resistant to soil stresses.

Muskmelon (Cucumis melo L.) is one of the most economically important cucurbits, cultivated in many tropical, subtropical and temperate regions around the world. Spain is the main producer in Europe with $\approx 43,000$ ha cultivated (F.A.O., 2000).

The terms "sudden wilt," "melon dieback," "vine decline," or "melon collapse" refer to a complex of soil borne fungal diseases that have become major yield-limiting factors in the United States, Israel, and Spain (GarcíaJiménez et al., 1989; Martyn and Miller, 1996; Pivonia et al., 1996). In Spain, the increasing incidence of vine decline diseases in the last 10 years has led to a $30 \%$ decrease in the melon cultivation area. Traditional muskmelon production on the eastern coast has almost been

Received for publication 21 June 2001. Accepted for publication 4 Mar. 2002. We thank Embrapa for providing a predoctoral fellowship to Rita Dias. The authors also acknowledge to the area of Plant Pathology of the Polytechnic Univ. of Valencia their technical assistance in fungi management. This research was supported by the CICYT project AGF97-1208-C03-02. abandoned due to collapse (Armengol, 1997). The primary pathogens responsible for melon vine decline in Spain are the soil borne fungi Monosporascus cannonballus Pollack and Uecker and Acremonium cucurbitacearum Alfaro-García, W. Gams, and J. GarcíaJiménez. These fungi cause damage to roots at all developmental stages, leading to a lateseason vine decline or collapse (GarcíaJiménez et al., 2000). Because of the loss of the plant's water-uptake capacity caused by root damaging soil fungi, the vine symptoms are exacerbated by high temperatures, dry winds, etc., at the time of fruit maturity (Iglesias et al., 2000a; Wolff and Miller, 1998).

Control of vine decline has been based mainly on methyl bromide fumigation prior to planting. Recently, restrictions on the use of methyl bromide have reinforced the need to identify alternative soil fumigants. Grafting melons onto resistant Cucurbita rootstocks is also a common practice in the Mediterranean basin. However, grafted plants are expensive and poor rootstock-scion compatibility may lead to yield reduction and poor fruit quality (Cohen et al., 2000). Breeding resistant melons is difficult and time-consuming because of the complex etiology (Bruton et al., 1998; GarcíaJiménez et al., 2000; Iglesias et al., 2000b; Pivonia et al., 1996) and importance of plantpathogen-environment interactions.

The accession Pat 81 of Cucumis melo subsp. agrestis has been selected as a source of resistance to vine decline after several field trials and screening assays in the greenhouse, using soil from infested fields and soil artificially inoculated with the pathogens (Iglesias and Nuez, 1998; Iglesias etal., 1999, 2000a, 2000b). Pat81 has a vigorous root system that could contribute to this accession's resistance to vine decline. Also, Crosby and Wolff (1998) and Crosby et al. (2000) associated the larger root area after inoculation of melons type 'Ananas' with their tolerance to vine decline. Moreover, root characteristics may offer unique genetic selection criteria for resistance to soil abiotic stresses (Clarke and McCaig, 1993; Leskovar and Stoffella, 1995; O’Toole and Bland, 1987).

The potential to improve root systems has not been extensively investigated for most vegetable crops. A major difficulty in studying root systems in soil is the high effect of edaphic and environmental factors on root growth, such as moisture, temperature, mineral concentration and gaseous atmosphere. Several root study methods have been used for destructive and nondestructive root sampling. Methodologies that minimize environmental effects should be selected in each case. Zobel (1986 and 1995) also suggests a sequential analysis of roots as the best way to obtain precise characterization.

The objectives of this study were to characterize the differences in root structure between two melon genotypes, a cultivated melon [C. melo cv. Amarillo Canario (AC)], susceptible to vine decline, and a wild resistant accession (C. melo subsp. agrestis Pat81), determining which root traits are more discriminant and the impact of pathogenic fungi on them. This information is useful to evaluate the potential of using Pat 81 as a source for breeding melons resistant to vine decline and more tolerant to stress.

Three sets of experiments were conducted: 1) a sequential analysis to identify useful root traits linked to vine decline resistance; 2) an assay to determine the effect of fungal infection on root structure of resistant vs. susceptible melons; and 3) an assay to study the effect of the soil on root structure.

\section{Materials and Methods}

Plant material. Three assays were conducted in the same greenhouse during the summer-autumn seasons of 1999 and 2000, using a pair of wild and cultivated taxa, the susceptible melon cv. AC, and the accession Cucumis melo subsp. agrestis Pat81, resistant to melon vine decline. All materials and techniques were the same for all experiments unless otherwise noted.

\section{Assay 1}

Sequential analysis of roots in healthy plants. Seeds were germinated in petri dishes. 
Seedlings were transplanted $4 \mathrm{~d}$ after sowing into $0.6-\mathrm{L}$ pots filled with pasteurized sand. The plants were hand-watered daily. After $15 \mathrm{~d}$, plants were carefully transplanted, to prevent root damage, into greenhouse benches (4 m long $\times 30 \mathrm{~cm}$ wide $\times 40 \mathrm{~cm}$ deep) also filled with sand (10 plants per bench). Plant spacing was uniform $(40 \mathrm{~cm})$ and wooden boards were used to keep each plant's roots separate from the others. The assay was conducted in Summer 1999. Growing temperatures in the greenhouse ranged from 25 to $30{ }^{\circ} \mathrm{C}$ day $/ 20$ to $25{ }^{\circ} \mathrm{C}$ night. Plants were watered four times per day using a microsprinkler irrigation system, and supplied with nutrient solutions appropriate for melon culture. All set fruits were removed from the plants.

The growth both above and below ground was measured on five different dates, 1,3, 6, 8, and 10 weeks after transplanting (WAT). Plants were assayed in a randomized block design with two blocks. Six plants of each accession per block were sampled on each date. After cutting the vine, the bench was flooded and root systems were pulled up carefully. The sand was flushed out with water. Entire root systems were placed in sealable plastic bags for storage. Shoots and roots were dried for at least $48 \mathrm{~h}$ to give dry weights.

Measurements were taken as follows: number of leaves (NL), shoot length (SL) $(\mathrm{cm})$, shoot fresh and dry weight (SFW and SDW) (g), crown diameter (CD) (mm), root fresh and dry weight (RFW and RDW) (g), maximum root length (MRL) $(\mathrm{cm})$, measured from the shoot base to the tip of the longest root, lateral root number with diameter $>0.5 \mathrm{~mm}$ (LRN) (lateral root was defined as a major root axis originating at the tap root), tap root length $(\mathrm{TRL})(\mathrm{cm})$, number of branches in the taproot (TRB), diameter of the taproot (TRD) $(\mathrm{mm})$ at $1 \mathrm{~cm}$ below the crown, at the midpoint, and $1 \mathrm{~cm}$ above the branching point.

Three different root indices were also used, a global index (GI) (scoring the vigor, length, branching pattern, and amount of lateral and fine roots from 0 to 4 ), a lateral roots index (LRI) (scoring the number, diameter and length of lateral roots with diameter $>0.5 \mathrm{~mm}$ from 0 to 4), and a fine roots index (FRI) (scoring the amount of fine roots with diameter $<0.5 \mathrm{~mm}$ from 0 to 4) (Iglesias et al., 2000b).

\section{Assay 2}

Analysis of roots in inoculated plants. Seeds were germinated in petri dishes, and transplanted to a seedling tray $4 \mathrm{~d}$ later. Seedlings were transplanted into $12-\mathrm{L}$ pots at the 2-true-leaf stage. The experiment was conducted using a soil mixture that contained two parts of naturally infested soil and one part of standard peat. The soil came from a field traditionally used for melon cultivation in Valencia (Eastern Spain). Previous studies indicated that isolates of $M$. cannonballus and $A$. cucurbitacearum from this field are more virulent than many other Spanish and American isolates (Iglesias et al., 2000b).
Natural soil was used to ensure maximum root damage, as it is difficult to get severe disease symptoms using artificial inoculation with only Monosporascus or Acremonium. The soil was thoroughly mixed with the peat to ensure uniform inoculum pressure. The assay was conducted in Summer 2000.

Ten plants per genotype were randomly arranged in the greenhouse. Additionally, four plants per genotype, cultivated in the same soil mixture, that had been sterilized (autoclaved three times for $1 \mathrm{~h}$, skipping one day between each autoclaving), were included as healthy controls. The latter were used as controls for fungal damage, but not for root development, since soil sterilization eliminated not only the pathogenic fungi but also the beneficial flora of the soil and plant development was delayed. The sampling was made at $10 \mathrm{WAT}$.

The same shoot and root parameters evaluated in Assay 1 were measured, except for the traits of the taproot. The length of the three longest lateral roots was considered (L1, L2, and L3). Lateral roots were grouped in two diameter classes (class $1=0.5-1 \mathrm{~mm}$; class 2 $=>1 \mathrm{~mm}$ ). Since it is very difficult to quantify the number of finer roots $(<0.5 \mathrm{~mm}$ in diameter), the branching pattern along L1, L2, and L3 was studied. The final two thirds of each root were completely separated, and the branching order (BO) measured. We consider L1, L2, and L3, roots emerging from the main root, as laterals of second order. Those laterals emerging from them are tertiary laterals. Laterals emerging from tertiary are laterals of fourth order, and so on, till the lateral of last order (Fitter, 1996). This parameter is related to the root capacity for exploiting a greater soil surface (Jackson, 1995).

Disease rating indices were used for the lesions in hypocotyls ( $\mathrm{LH})$, lesions in lateral roots $(>0.5 \mathrm{~mm}$ in diameter) (LLR), and lesions in the finest roots $(<0.5 \mathrm{~mm}$ in diameter) (LFR). Each index was scored from 0 , healthy with no lesions or discoloration like the noninoculated controls, to 4 , severe discoloration, browning and necrosis.

Isolations were made from random sampled plants of each genotype as reported in Iglesias et al. (2000b) to verify the presence of fungi. Small portions of roots were plated on petri dishes with PDA medium (potato-dextrose-agar), supplemented with $0.5 \mathrm{~g} \cdot \mathrm{L}^{-1}$ of streptomycin sulphate. The petri dishes were incubated for $15 \mathrm{~d}$ at $26{ }^{\circ} \mathrm{C}$. Daylight was supplemented with ultraviolet light to encourage sporulation, necessary for fungal identification.

\section{Assay 3}

Effect of the substrate on root structure. Seeds were germinated in petri dishes and $4 \mathrm{~d}$ later were transplanted to $0.6-\mathrm{L}$ pots. The assay was conducted in Summer 2000.

A factorial design was used with two factors, genotype with two levels: AC and Pat81; and substrate with five levels: sand, two kinds of peat, standard (sp), and well decomposed peat (dp), $1 \mathrm{sp}: 3$ sand, and $1 \mathrm{dp}: 3$ sand. Peat characteristics were: 1) sp, a commercial standard peat ( $\mathrm{pH} 5.5$; organic matter content $90 \% ; 160 \mathrm{~N}-120 \mathrm{P}-200 \mathrm{~K}\left(\mathrm{mg} \cdot \mathrm{L}^{-1}\right) ; \mathrm{S}=$ $80 \mathrm{mg} \cdot \mathrm{L}^{-1} ; \mathrm{Mg}=4 \mathrm{mg} \cdot \mathrm{L}^{-1} ; \mathrm{Ca}=120 \mathrm{mg} \cdot \mathrm{L}^{-1}$; $\mathrm{B}=0.3 \mathrm{mg} \cdot \mathrm{L}^{-1} ; \mathrm{Cu}=0.1 \mathrm{mg} \cdot \mathrm{L}^{-1} ; \mathrm{Mn}=0.7 \mathrm{mg}$ $\mathrm{L}^{-1} ; \mathrm{Zn}=0.2 \mathrm{mg} \cdot \mathrm{L}^{-1} ; \mathrm{Fe}=2 \mathrm{mg} \cdot \mathrm{L}^{-1} ; \mathrm{Mb}=0.02$ $\mathrm{mg} \cdot \mathrm{L}^{-1}$ ); and 2) dp, a mixture of peats with different decomposition degrees, usually used for seedling growth ( $\mathrm{pH}$ 5.5-6.5; organic matter content $90 \% ; 140 \mathrm{~N}-70 \mathrm{P}-150 \mathrm{~K}\left(\mathrm{mg} \cdot \mathrm{L}^{-1}\right)$; $\mathrm{S}=76 \mathrm{mg} \cdot \mathrm{L}^{-1} ; \mathrm{Mg}=4.2 \mathrm{mg} \cdot \mathrm{L}^{-1} ; \mathrm{B}=$ $0.3 \mathrm{mg} \cdot \mathrm{L}^{-1} ; \mathrm{Cu}=1.2 \mathrm{mg} \cdot \mathrm{L}^{-1} ; \mathrm{Mn}=1.6 \mathrm{mg} \cdot \mathrm{L}^{-1}$; $\mathrm{Zn}=0.4 \mathrm{mg} \cdot \mathrm{L}^{-1} ; \mathrm{Fe}=0.9 \mathrm{mg} \cdot \mathrm{L}^{-1} ; \mathrm{Mb}=$ $\left.2 \mathrm{mg} \cdot \mathrm{L}^{-1}\right)$. Four plants per block, genotype and substrate were arranged in a randomized block design, with two blocks.

The sampling was made at 4 WAT. The shoot traits NL, SFW, and SDW were measured. An additional global index was used for shoot development (SGI), scored from 0 (small plants, with thin stems and few leaves) to 4 (vigorous plants, long, branched, with wide stems, and many leaves). Roots were pulled out of the pots and washed as previously described. The time spent in washing each root (WT) (s) and a cleaning index (CI) $(0=$ clean root, to $4=$ root with substrate residues) was measured. The root traits MRL, RFW, RDW, and GI were also evaluated.

Each root system was dipped into a $1 \%$ aceto orcein solution for several minutes. After being washed in water, the root was placed on a clear glass over a milimetric paper, submerged in a thin layer of water, and spaced using dissecting needles. Stained roots were then scanned, and a more detailed characterization was performed. The lateral roots were grouped in three length classes (class $1=2$ to $6 \mathrm{~cm}$, class $2=6$ to $14 \mathrm{~cm}$, class $3=>14 \mathrm{~cm}$ ). Additionally, the total surface area of each root (RSA) $\left(\mathrm{cm}^{2}\right)$ was measured using image analysis software (Scion Image, Beta 4.0.2; Scion Corp., National Institutes of Health, Bethesda, Md.).

An additional experiment was carried out to verify the root traits, which best differentiated the genotypes, using the substrate selected in the previous assay. Plants were transplanted into $12-\mathrm{L}$ pots. The assay was conducted in Summer/Autumn 2000. Ten plants per genotype were randomly arranged in the greenhouse. Sampling was conducted at 7 WAT (flowering time). The traits MRL, RFW, RDW, LRN, BO in the three largest roots, and GI were measured in each root.

Data analysis. Data was subjected to multiple and one-way analysis of variance (ANOVA) and to means separation analysis (Newman-Keuls test). The correlation among traits was studied by the product-moment correlation coefficient $\left(r_{x y}\right)$.

\section{Results and Discussion}

Sequential analysis of roots in healthy plants. The crown diameter (CD) was highly correlated to the number of leaves (NL) $\left(r_{x y}=\right.$ $0.9, P<0.01)$, and the shoot and root dry weights (SDW and RDW) were highly correlated to the fresh weights (SFW and RFW) 


\section{Breeding, Cultivars, Rootstocks, \& Germplasm Resources}

respectively $\left(r_{x y}=0.99, P<0.01\right.$ in both cases $)$. Therefore these data were excluded from the analysis.

Clear differences in the growth pattern were found between the two genotypes (Table 1). Shoot biomass (SL and SFW) was higher in $\mathrm{AC}$ at the initial developmental stages. The situation changes from 6 WAT on, and plants of Pat81 tended to be longer and heavier, but differences were only significant at 10 WAT. The greater size of the AC seed compared with Pat81 (AC $=2.4 \mathrm{~g} / 100$ seeds; Pat81 $=1.2 \mathrm{~g} /$
100 seeds), could explain these initial differences in growth. A similar effect of the seed size on the seedling growth has been previously reported in other crops (Jackson, 1995).

Throughout the 10-week period, there were no significant differences between genotypes for most of the taproot traits (branching, and diameters) (data not shown). However, differences existed for the rest of root traits. By week 6 , roots of both genotypes were similar, and by the end of the assay Pat 81 had significantly longer roots and greater fresh weights
(Table 1 and Fig. 1A). Pat81 also produced more lateral roots with diameter $>0.5 \mathrm{~mm}$ (LRN). During root characterization, roots finer than $0.5 \mathrm{~mm}$ (mostly 0.1 to $0.3 \mathrm{~mm}$ in diameter) were more commonly observed in Pat81 than in AC. It was very difficult to quantify these fine laterals, so the amount of roots was included in the FRI. The indices scores were consistent with the previous parameters. The roots of $\mathrm{AC}$ had better scores for GI and LRI at 3 WAT, but at the final sampling date (10 WAT) Pat81 had better scores for the

Table 1. Shoot and root characteristics of C. melo cv. Amarillo Canario (AC) and the wild accession C. melo subsp. agrestis Pat 81 grown in sand at five sampling dates (Assay 1).

\begin{tabular}{|c|c|c|c|c|c|c|c|c|c|c|}
\hline \multirow[b]{3}{*}{ Traits } & \multicolumn{10}{|c|}{ Weeks after transplanting } \\
\hline & \multicolumn{2}{|c|}{1} & \multicolumn{2}{|c|}{3} & \multicolumn{2}{|c|}{6} & \multicolumn{2}{|c|}{8} & \multicolumn{2}{|c|}{10} \\
\hline & $\mathrm{AC}$ & Pat81 & $\mathrm{AC}$ & Pat81 & $\mathrm{AC}$ & Pat81 & $\mathrm{AC}$ & Pat81 & $\mathrm{AC}$ & Pat81 \\
\hline & & & & & & - (Flowe & g time) & & & \\
\hline Number of leaves & $0^{z}$ & 0 & 4.7 & 5 & 18.5 & 39 & 34 & 92.3 & 54.3 & $226.3^{*}$ \\
\hline Shoot length $(\mathrm{cm})$ & 2.1 & 2.4 & 12.6 & $5.4^{*}$ & 90.9 & 125 & 204.8 & 188 & 263 & 305.7 \\
\hline Shoot fresh weight $(\mathrm{g})$ & 0.07 & $0.03^{*}$ & 1.3 & 0.7 & 46.3 & 46.3 & 125.9 & 263.2 & 541.3 & $783.3^{*}$ \\
\hline Maximum root length $(\mathrm{cm})$ & 2.3 & 3.6 & 12.4 & 10.7 & 66.4 & 50.3 & 55.6 & 49.9 & 62.9 & $117.4^{*}$ \\
\hline Lateral root number & & & & & & & & & & \\
\hline (diameter $>0.5 \mathrm{~mm})$ & 0 & 0 & 2.3 & 0 & 3 & 7.5 & 11 & 10.3 & 9 & $15^{*}$ \\
\hline Root fresh weight (g) & 0.005 & 0.007 & 0.5 & 0.2 & 3.7 & 3.5 & 3.9 & 6.3 & 26.2 & $89.4^{*}$ \\
\hline Global index $x^{y}$ & --- & --- & 3 & $2^{*}$ & 1.5 & 2 & 1.7 & 2 & 3.3 & 3.7 \\
\hline Lateral roots index ${ }^{y}$ & --- & --- & 3.7 & $2^{*}$ & 1 & 2 & 1.7 & 2 & 2.3 & $3.7^{*}$ \\
\hline Fine Roots Index ${ }^{y}$ & --- & --- & 2 & 1.3 & 2 & 2 & 2 & 2 & 2.3 & $3.7^{*}$ \\
\hline
\end{tabular}

${ }^{2}$ For each row and sampling date $(*)$ indicates significant differences between $\mathrm{AC}$ and Pat $81(P<0.05)$ according a Newman-Keuls multiple range test. There were no significant differences between blocks so data were grouped and each data is the mean of 12 plants. 'Indices were scored from 0 to 4 . Global index from 0 (small and short roots, with few laterals and fine roots) to 4 (vigorous roots, long and branched, with a great amount of fine roots); Lateral root index from 0 (roots with very few short laterals with diameter $>0.5 \mathrm{~mm}$ ) to 4 (roots with many long laterals with diameter $>0.5 \mathrm{~mm}$ ); Fine roots index from 0 (roots with a low amount of fine roots with diameter $<0.5 \mathrm{~mm}$ ) to 4 (roots with a great amount of fine roots with diameter $<0.5 \mathrm{~mm}$ ).
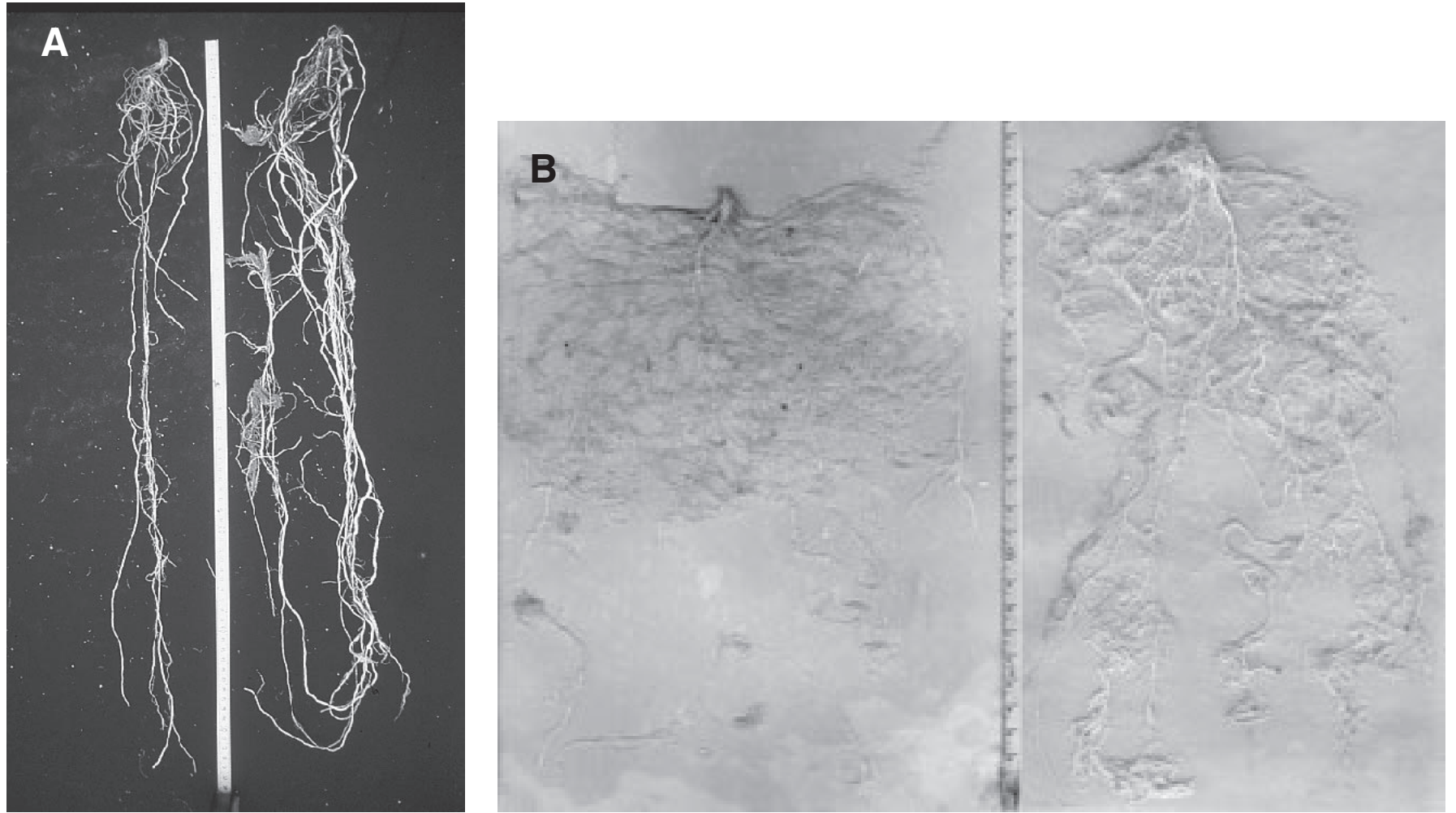

Fig. 1. (A) Roots of Pat81 (left) and Amarillo Canario (AC) (right) cultivated in sand and sampled at 10 weeks after transplanting (Assay 1). Pat81 had longer roots with more laterals and better scores for the fine roots index. (B) Roots of Pat81 (right) and AC (left) cultivated in 1 decomposed peat : 3 sand and sampled at 7 weeks after transplanting (Assay 3). Roots were placed on a clear glass, submerged in a thin layer of water, and spaced using dissecting needles. Pat81 developed significantly longer roots, with a high number of fine laterals and a higher branching order. 
LRI and the FRI (Table 1).

These differences are to be expected between a cultivated and a wild accession. Cultivated melons have been bred for desirable growth in vegetable production systems with high inputs of nutrients and frequent irrigation. However, the root structure of Pat81 could confer it a greater capacity of adaptation to drier, poorer soil conditions. Also, Pantalone et al. (1996) associated a more branched roots system, with a greater amount of fine roots, with an increase in drought tolerance in soybean. Whether the root structure of Pat81 may contribute to tolerance to melon vine decline or not needs to be confirmed by studying root differences after fungal damage in inoculated plants.

Analysis of roots in inoculated plants. Fungal lesions were significantly less severe in roots of Pat81 compared to AC (Table 2), mainly in hypocotyls (LH) and also in lateral roots (LLR) and in the finest roots (LFR).

M. cannonballus and A. cucurbitacearum were the fungi most frequently isolated from damaged roots. Other fungi were isolated sporadically, i.e., some species of the genera Rhizoctonia, Macrophomina, Rhizopycnis, Pythium, Trichoderma, Fusarium, etc.

The more discriminatory root traits between genotypes in Assay 1, also differentiated diseased roots of both genotypes. Significant differences were found in root length and branching parameters (L3 and LRN, diameter 0.5 to $1 \mathrm{~mm}$ ) following inoculation (Table 2). The wild genotype developed more lateral roots, which were longer. The branching order was also highly discriminatory, being $25 \%$ higher in Pat81 compared to AC. A higher branching order implies a higher amount of finer roots. Therefore, the root structure of
Pat81 provides this accession a greater root absorbent area even in inoculated soils. This could help to increase the level of tolerance to the disease. Crosby et al. (2000), after inoculation with Monosporascus cannonballus, found a greater total root length, length of fine and small roots, and a higher number of root tips in melon cultivars 'Deltex' and 'Doublon', tolerant to vine decline, compared to susceptible cultivars.

Effect of the substrate on root structure. Root differences between Pat 81 and AC and their correlation with vine decline resistance can be drawn from the Assays 1 and 2. However, in Assay 1, evident differences between genotypes did not appear until the end of the growing cycle. In Assay 2, the root characterization was highly tedious and time-consuming. We employed a lot of time in washing and characterizing each root to prevent an occa-

Table 2. Shoot and root characteristics of C. melo cv. Amarillo Canario (AC) and the wild accession C. melo subsp. agrestis Pat81 after inoculation using naturally infested soil (sampling was conducted at 10 weeks after transplanting, Assay 2).

\begin{tabular}{|c|c|c|c|c|c|}
\hline Traits & $\mathrm{AC}$ & Pat81 & Traits & $\mathrm{AC}$ & Pat81 \\
\hline Number of leaves & $95.8^{\mathrm{z}}$ & $177.1^{*}$ & Lateral root number (diam. $>1 \mathrm{~mm}$ ) & 20.2 & 18.4 \\
\hline Shoot length $(\mathrm{cm})$ & 240.2 & 229.1 & Branching order & 4.6 & $5.8^{*}$ \\
\hline Shoot fresh weight (g) & 470 & 489.5 & Global index ${ }^{x}$ & 2.4 & $3.9^{*}$ \\
\hline Root fresh weight $(\mathrm{g})$ & 60.4 & 63.7 & Lateral roots index ${ }^{\mathrm{w}}$ & 3 & $4^{*}$ \\
\hline $\mathrm{L}^{\mathrm{y}}(\mathrm{cm})$ & 82.6 & 107.1 & Fine roots index ${ }^{v}$ & 2.8 & $3.7^{*}$ \\
\hline $\mathrm{L} 2^{\mathrm{y}}(\mathrm{cm})$ & 65.4 & 87.1 & Lesions in hypocotyl ${ }^{u}$ & 3.4 & $0.23^{*}$ \\
\hline $\mathrm{L}^{\mathrm{y}}(\mathrm{cm})$ & 52.1 & $75.4^{*}$ & Lesions in lateral roots $(>0.5 \mathrm{~mm} \text { diam. })^{\mathrm{u}}$ & 3.2 & $1.2^{*}$ \\
\hline Lateral root number $(0.5-1 \mathrm{~mm}$ diam.) & 1.2 & $6.4^{*}$ & Lesions in fine roots $(<0.5 \mathrm{~mm} \text { diam. })^{\mathrm{u}}$ & 3.4 & $1.8^{*}$ \\
\hline
\end{tabular}

${ }^{2}$ For each row $(*)$ indicates significant differences between AC and Pat81 $(P<0.05)$ according to a Newman-Keuls multiple range test. Each data is the mean of 10 plants.

${ }^{y} \mathrm{~L} 1, \mathrm{~L} 2$, and L3 $=$ length of the three longest lateral roots

${ }^{x}$ Global index on a scale of 0 to 4 , where $0=$ small and short roots, with few laterals and fine roots, and $4=$ vigorous roots, long and branched, with a great amount of fine roots.

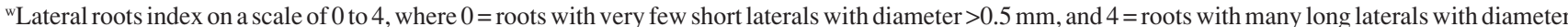
$>0.5 \mathrm{~mm}$.

${ }^{\vee}$ Fine roots index on a scale of 0 to 4 , where $0=$ roots with a low amount of fine roots with diameter $<0.5 \mathrm{~mm}$, and $4=$ roots with a great amount of fine roots with diameter $<0.5 \mathrm{~mm}$.

"Disease indices were scored on a scale of 0 to 4 , where $0=$ healthy roots, and $4=$ roots severely affected.

Table 3. Shoot and root characteristics of C. melo cv. Amarillo Canario (AC) and the wild accession C. melo subsp. agrestis Pat 81 cultivated in different soil substrates (sampling was conducted at 4 weeks after transplanting, Assay 3).

\begin{tabular}{|c|c|c|c|c|c|c|c|c|}
\hline & \multicolumn{2}{|c|}{ Shoot global index ${ }^{2}$} & \multicolumn{2}{|c|}{ No. of leaves } & \multicolumn{2}{|c|}{ Shoot fresh wt (g) } & \multicolumn{2}{|c|}{ Washing time (s) } \\
\hline & $\mathrm{AC}$ & Pat81 & $\mathrm{AC}$ & Pat81 & $\mathrm{AC}$ & Pat81 & $\mathrm{AC}$ & Pat81 \\
\hline Decomposed peat/sand $(1: 3)$ & $2.5 \mathrm{~b}$ & $2.9 \mathrm{bc}$ & $3.1 \mathrm{~b}$ & $4 \mathrm{~b} / *$ & $2.2 \mathrm{bc}$ & $1.5 \mathrm{~b}$ & $50.3 \mathrm{~b}$ & $61.4 \mathrm{~b}$ \\
\hline Standard peat/sand $(1: 3)$ & $2.4 \mathrm{~b}$ & $2.3 \mathrm{~b}$ & $2.8 \mathrm{~b}$ & $4.3 \mathrm{bc} / *$ & $1.6 \mathrm{ab}$ & $0.8 \mathrm{ab} / *$ & $65.1 \mathrm{bc}$ & $56.1 \mathrm{~b}$ \\
\hline \multirow[t]{2}{*}{ Standard peat } & $4 \mathrm{c}$ & $3.4 \mathrm{~cd} / *$ & $3.8 \mathrm{~b}$ & $5.1 \mathrm{~cd} / *$ & $4.8 \mathrm{~d}$ & $3.1 \mathrm{c} / *$ & $84.5 \mathrm{~cd}$ & $102.6 \mathrm{~b}$ \\
\hline & \multicolumn{6}{|c|}{$P$ value } & \\
\hline Effect of genotype & \multicolumn{2}{|c|}{0.5321} & \multicolumn{2}{|c|}{$\begin{array}{l}0.0000 \\
0.0000\end{array}$} & \multicolumn{2}{|c|}{0.0004} & \multicolumn{2}{|c|}{0.5211} \\
\hline \multirow{2}{*}{ Effect of interaction } & \multicolumn{2}{|c|}{ Cleaning index ${ }^{z}$} & \multicolumn{2}{|c|}{ Global index ${ }^{2}$} & \multicolumn{2}{|c|}{ Maximum root length $(\mathrm{cm})$} & \multicolumn{2}{|c|}{ Root fresh wt (g) } \\
\hline & $\mathrm{AC}$ & Pat81 & $\mathrm{AC}$ & Pat81 & $\mathrm{AC}$ & Pat81 & $\mathrm{AC}$ & Pat81 \\
\hline Sand & \multicolumn{2}{|c|}{$0 \mathrm{a}^{\mathrm{x}}$} & \multicolumn{2}{|c|}{$0.7 \mathrm{a}^{\mathrm{x}}$} & \multicolumn{2}{|c|}{$6.4 \mathrm{a}^{\mathrm{x}}$} & $0.07 \mathrm{a}$ & $0.02 \mathrm{a} /{ }^{*}$ \\
\hline Decomposed peat/sand $(1: 3)$ & \multicolumn{2}{|c|}{$2.1 \mathrm{bc}$} & \multicolumn{2}{|c|}{$3.7 \mathrm{bc}$} & \multicolumn{2}{|c|}{$19.3 \mathrm{c}$} & $0.15 \mathrm{ab}$ & $0.24 \mathrm{c}$ \\
\hline Decomposed peat & \multicolumn{2}{|c|}{$2.5 \mathrm{c}$} & \multicolumn{2}{|c|}{$3.2 \mathrm{~b}$} & \multicolumn{2}{|c|}{$15.7 \mathrm{~b}$} & $0.1 \mathrm{a}$ & $0.16 \mathrm{bc} /{ }^{*}$ \\
\hline Standard peat/sand (1:3) & \multicolumn{2}{|c|}{$1.5 \mathrm{~b}$} & \multicolumn{2}{|c|}{$3.5 \mathrm{~b}$} & \multicolumn{2}{|c|}{$18.4 \mathrm{bc}$} & $0.23 \mathrm{bc}$ & $0.1 \mathrm{ab}$ \\
\hline Effect of interaction & & & & & & & & \\
\hline
\end{tabular}

${ }^{2}$ Indices were scored from 0 to 4.

${ }^{y}$ Numbers in the same column followed by the same letter are not significantly different at $P<0.01$ according to a Newman-Keuls multiple range test. For each row (*) indicates significant differences $P<0.01$ between AC and Pat 81 . Differences between blocks were not significant so data from the two blocks were grouped. Each data is the mean of eight plants.

${ }^{x}$ The data have been combined over genotype because the main effects of genotype or substrate interactions were not significant. Each data is the mean of 16 plants. 
Table 4. Number of lateral roots, grouped in three length classes, of C. melo cv. Amarillo Canario (AC) and the wild accession C. melo subsp. agrestis Pat 1 cultivated in different substrates. (Sampling was conducted at 4 weeks after transplanting, Assay 3).

\begin{tabular}{|c|c|c|c|c|c|c|}
\hline & \multicolumn{6}{|c|}{ Lateral root number } \\
\hline & \multicolumn{2}{|c|}{$2-6 \mathrm{~cm}$} & \multicolumn{2}{|c|}{$6-14 \mathrm{~cm}$} & \multicolumn{2}{|c|}{$14-20 \mathrm{~cm}$} \\
\hline & $\mathrm{AC}$ & Pat81 & $\mathrm{AC}$ & Pat81 & $\overline{\mathrm{AC}}$ & Pat81 \\
\hline Sand & $3 \mathrm{a}^{\mathrm{z}}$ & $0.8 \mathrm{a}$ & $1 \mathrm{a}^{\mathrm{z}}$ & $0 \mathrm{a}$ & & \\
\hline Decomposed peat/sand $(1: 3)$ & $5.4 \mathrm{ab}$ & $6.5 \mathrm{bc}$ & $6.8 \mathrm{c}$ & $5.1 \mathrm{c}$ & & $3 \mathrm{~b}$ \\
\hline Decomposed peat & $8 \mathrm{bc}$ & $7.5 \mathrm{c}$ & $3.3 \mathrm{ab}$ & $3.5 \mathrm{~b}$ & & \\
\hline Standard peat/sand $(1: 3)$ & $9.8 \mathrm{c}$ & $7.6 \mathrm{c} / *$ & $7 \mathrm{c}$ & $3.9 \mathrm{~b} / *$ & & \\
\hline Standard peat & $8.7 \mathrm{bc}$ & $6.1 \mathrm{bc}$ & $4.5 \mathrm{~b}$ & $3.9 \mathrm{~b}$ & & $3 a b$ \\
\hline \multicolumn{7}{|c|}{$P$ value } \\
\hline Effect of genotype & \multicolumn{2}{|c|}{0.0005} & \multicolumn{2}{|c|}{0.0041} & & 887 \\
\hline Effect of substrate & \multicolumn{2}{|c|}{0.0000} & \multicolumn{2}{|c|}{0.0000} & & 195 \\
\hline Effect of interaction & \multicolumn{2}{|c|}{0.0267} & \multicolumn{2}{|c|}{0.3826} & & 062 \\
\hline
\end{tabular}

${ }^{2}$ Numbers in the same column followed by the same letter are not significantly different at $P<0.01$ according to a Newman-Keuls multiple range test. For each row $(*)$ indicates significant differences $P<0.01$ between $\mathrm{AC}$ and Pat81. Differences between blocks were not significant so data from the two blocks were grouped. Each data is the mean of eight plants.

${ }^{y}$ The data have been combined over genotype because the main effects of genotype or substrate interactions were nonsignificant. Each data is the mean of 16 plants.

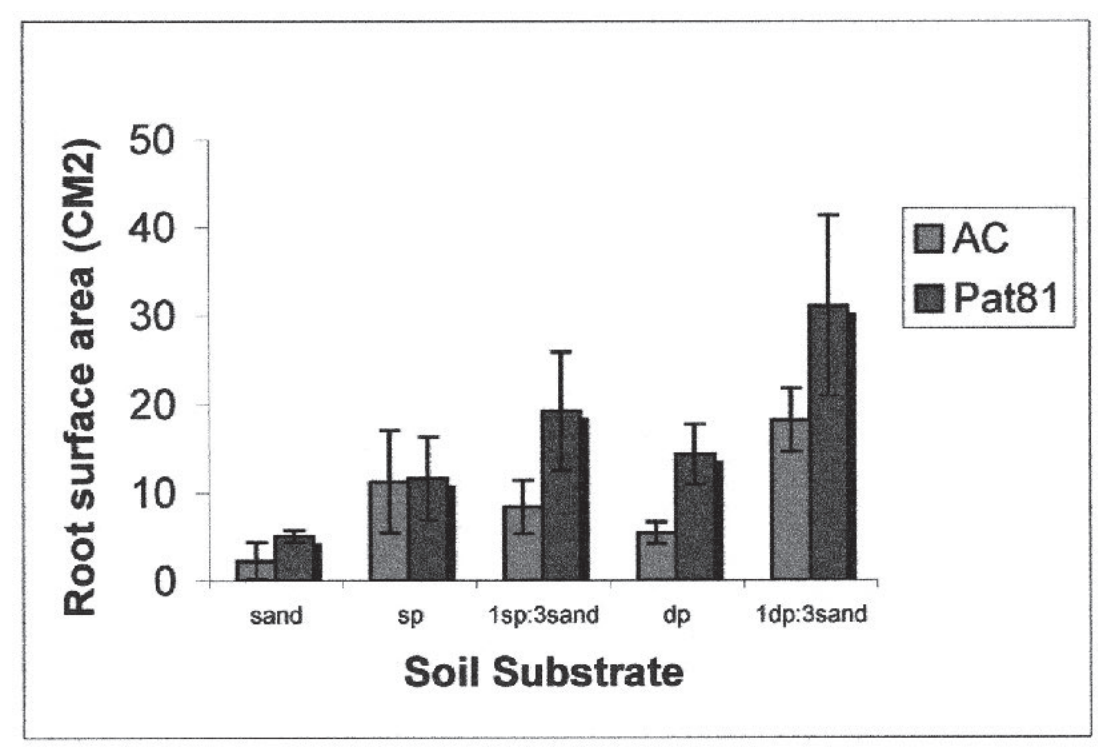

Fig. 2. Root surface area of C. melo cv. Amarillo Canario (AC) and the wild accession C. melo subsp. agrestis Pat 81 cultivated in different substrates (Each data is the mean of five plants, bars indicate the standard errors, $\mathrm{sp}=$ standard peat, $\mathrm{dp}=$ well decomposed peat).

sional rupture of the finest roots in the natural heavy clay soil.

Other soil substrates should be assayed in order to bring the discriminatory sampling date forward, confirming the root differences between genotypes. Multifactor ANOVA revealed significant differences $(P<0.01)$ among soil substrates for all shoot and root traits and between genotypes for some shoot and root traits (Tables 3 and 4). In addition, substrate $\times$ genotype interactions were sig- to those obtained in Assay 1, with better root development for AC.

In the other substrates, the development of $\mathrm{AC}$ and Pat81 was similar at the sampling stage (4 WAT) (Table 3 and 4). This situation occurred much later in Assay 1 (from 6 WAT). The mixtures $1 \mathrm{sp}: 3$ sand and $1 \mathrm{dp}: 3$ sand produced significantly longer laterals (6-14 $\mathrm{cm}$ ) than sp and dp. This effect is very clear in $\mathrm{AC}$, but only appeared in Pat 81 in the $1 \mathrm{dp}: 3$ sand substrate. The lower degree of decomposition of the standard peat caused rupture of some lateral roots during washing. This rupture was more relevant in Pat81 where finer roots appeared. Indeed, differences for LRN $(2-14 \mathrm{~cm})$ between AC and Pat81 were nonsignificant in $1 \mathrm{dp}: 3$ sand, but were significant in $1 \mathrm{sp}: 3$ sand (Table 4). Image analysis gave information about the root surface area (Fig. 2). Differences for root surface area between Pat81 and AC were important for $\mathrm{dp}$ $(P$ value $=0.031), 1 \mathrm{dp}: 3$ sand $(P$ value $=$ $0.109)$, and $1 \mathrm{sp}: 3$ sand $(P$ value $=0.0439)$, but not for sp $(P$ value $=0.944)$.

Results demonstrated the existence of clear effects of the substrate on root development and root morphology. This effect has been previously reported in other vegetables. O'Toole and Bland (1987) and Clarke and McCaig (1993) concluded that a primary constraint to root system improvement is its extensive morphological plasticity. This plasticity results in a drastic change in the root system morphology within homozygous genotypes. The interactions of the genotype with the environment are favorable for the plant allowing it to survive in diverse soil environments. However, a large $\mathrm{G} \times \mathrm{E}$ interaction can make the characterization of roots difficult in a breeding program. From the results, we selected the $1 \mathrm{dp}: 3$ sand mixture as the soil substrate that better facilitated root washing and in which genotype $\times$ substrate interactions where minimized. However, differences between genotypes were not significant for most root traits at the sampling stage assayed. This soil substrate was used in a new assay delaying the sampling stage to the flowering time (7 WAT). Significant differences between genotypes were then observed for most root traits (Table 5). Pat 81 developed $25 \%$ longer roots, with a higher number of finer lateral roots $(0.5-1 \mathrm{~mm}$ in diameter) (almost three times greater in Pat81 than in AC), and 30\% higher branching order (Fig. 1B). The root area was not evaluated because of the root size. At this developmental stage, roots were too big and complex to get a precise computerized image. Indeed, digital image analysis is being used to quantify

Table 5. Root characteristics of C. melo cv. Amarillo Canario (AC) and the wild accession C. melo subsp. agrestis PAT 81 cultivated in 1 decomposed peat : 3 sand (sampling was conducted at 7 weeks after transplanting, Assay 3 ).

\begin{tabular}{lcccccc}
\hline \hline Genotype & $\begin{array}{c}\text { Maximum } \\
\text { root length }(\mathrm{cm})\end{array}$ & $\begin{array}{c}\text { Lateral root no. } \\
(0.5-1 \mathrm{~mm} \text { diam })\end{array}$ & $\begin{array}{c}\text { Lateral root no. } \\
(1 \mathrm{~mm} \text { diam })\end{array}$ & $\begin{array}{c}\text { Branching } \\
\text { order }\end{array}$ & $\begin{array}{c}\text { Root fresh wt } \\
(\mathrm{g})\end{array}$ & $\begin{array}{c}\text { Global } \\
\text { index }^{\mathrm{y}}\end{array}$ \\
\hline Pat81 & $41.8^{\mathrm{z}}$ & 7.8 & 4.7 & 4.6 & 32.2 & 3.7 \\
AC & 33.4 & $2.7^{*}$ & 4.5 & $3.7^{*}$ & $11.4^{*}$ & $2.7^{*}$ \\
\hline
\end{tabular}

${ }^{ }$For each column $(*)$ indicates significant differences between AC and Pat $81(P<0.05)$ according to a Newman-Keuls multiple range test. Each data is the mean of 10 plants.

${ }^{y}$ Global index was scored from 0 (small and short roots, with few laterals and fine roots) to 4 (vigorous roots, long and branched, with a great amount of fine roots). 
the response of melons to root rot pathogens in young roots characterized around 4 WAT (Biernacki and Bruton, 2001).

\section{Conclusions}

Cucumis melo subsp. agrestis Pat81 developed a more vigorous and branched root system than cultivated melon accessions in noninoculated soils. Previous studies on melon root systems are very scarce. Most of them deal with breeding melons for vine decline resistance, screening only cultivated melons with similar root systems in healthy soils (Crosby et al., 2000; Wolff and Miller, 1998).

The work with wild species is quite recent (Iglesias and Nuez, 1998; Iglesias et al., 1999). The importance of $\mathrm{G} \times$ E interactions increases when working with wild accessions such as Pat81. Differential adaptation of Pat81, compared with the cultivated accessions, to the substrates used could lead to erroneous conclusions in the selection process. In our study the use of sand as soil substrate delayed the appearance of root differences between genotypes, which appeared earlier in organic substrates such as peat and sand mixtures. Despite the high plasticity of root systems, some root traits such as root length, number of lateral roots, and branching order differentiated Pat 81 from AC in different soil substrates, culture conditions, and growing cycles. Selection for these favorable root characteristics could be performed to increase stress tolerance in melons.

Significant differences in lesion rating between Pat81 and $\mathrm{AC}$ indicate a resistance mechanism to vine decline in the wild accession. This mechanism could be distinct from root vigor, for example lesions in hypocotyl are unlikely to be associated to root structure. Selection for lesion intensity could lead to a specific resistance to pathogenic fungi responsible for vine decline. In addition, differences in root structure between $\mathrm{AC}$ and $\mathrm{Ag}$ remain after inoculation. The root structure of Pat81 provides this accession with a greater root absorbent area even in inoculated soils. Therefore, selection for favorable root characteristics could also help to increase the level of tolerance to the disease.

Crosby (2000) characterized three wild melon PI accessions and their crosses to cultivated melons. He did not find differences in length and root surface area among noninoculated plants of wild and cultivated resistant or susceptible genotypes. Root differences only appeared after fungal damage.
This partially agrees with our results as this author sampled at $30 \mathrm{~d}$ after sowing, and we did not find clear differences between genotypes at early sampling dates. This author did not study differences between resistant and susceptible accessions at the end of the growing cycle.

In many growing areas in Spain, muskmelon varieties are being grafted onto resistant $C$ ucurbita stocks, with vigorous root systems, to avoid problems caused by root pathogens and soil stresses. This strategy is increasing the growing costs of this crop. By using segregant populations derived from the cross AC $\times$ Pat81, we are trying to genetically imitate the "grafting strategy" by developing muskmelon cultivars with more vigorous and branched root systems and with more resistance to vine decline.

\section{Literature Cited}

Armengol, J. 1997. Aspectos patológicos, epidemiológicos y culturales de Acremonium cucurbitacearum Alfaro-García, W. Gams et García-Jiménez. PhD Thesis, Dept. of Plant Pathology, Universidad Politécnica de Valencia, Spain.

Biernacki, M. and B.D. Bruton. 2001. Quantitative response of Cucumis melo inoculated with root rot pathogens. Plant Dis. 85:65-70.

Bruton, B.D., V.M. Russo, J. García-Jiménez, and M. Miller. 1998. Carbohydrate partitioning, cultural practices, and vine decline diseases of cucurbits, p. 189-200. In: J. McCreight (ed.). Cucurbitaceae 1998. ASHS Press, Alexandria, Va.

Clarke, J.M. and T.N. McCaig. 1993. Breeding for efficient root systems, p. 485-499. In: M.D. Hayward, N.O. Bosemark, and I. Romagosa (eds.). Plant breeding: Principles and prospects. Chapman and Hall, London.

Cohen, R., S. Pivonia, Y. Burger, M. Edelstein, A. Gamliel, and J. Katan. 2000. Various approaches toward controlling sudden wilt of melons en Israel. Acta Hort. 510:143-147.

Crosby, K. and D. Wolff. 1998. Effects of Monosporascus cannonballus on root traits on susceptible and tolerant melon (Cucumis melo L.), p. 253-256. In: J. McCreight (ed.). Cucurbitaceae 1998. ASHS Press, Alexandria, Va.

Crosby, K. 2000. Narrow-sense heritability estimates for root traits and Monosporascus cannonballus tolerance in melon (Cucumis melo) by parent offspring regression. Acta Hort. 510:149-155.

Crosby, K., D. Wolff, and M. Miller. 2000. Comparisons of root morphology in susceptible and tolerant melon cultivars before and after infection by Monosporascus cannonballus. HortScience 35:681-683.
F.A.O. (2000). Statistics of Cantaloupes and others melons production. FAOSTAT Database Results. HtmlResAnchor URL:http://apps.fao.org/ page/.

Fitter, A. 1996. Characteristics and functions of root systems, p. 1-20. In: Y. Waisel, A. Eshel, and U. Kafkafi (eds.). Plant roots. The hidden half. Marcel Dekker, New York.

García-Jiménez, J., M.T. Velázquez, and A. Alfaro. 1989. Secuencia de síntomas en el colapso del melón. Bol. San. Veg. Plagas 4:333-342.

García-Jiménez, J., J. Armengol, R. Sales, C. Jordá, and B.D. Bruton. 2000. Fungal pathogens associated with melon collapse in Spain. EPPO Bul. 30:169-173.

Iglesias, A. and F. Nuez. 1998. Caracterización de diversas entradas de melón frente al colapso o muerte súbita. Actas de Horticultura 22:139147.

Iglesias A., B. Picó, and F. Nuez. 1999. C. melo spp. agrestis, Pat81, an interesting genetic resource highly resistant to melon dieback. Phytopathology $89:$ :S35.

Iglesias A., B. Picó, and F. Nuez. 2000a. A temporal genetic analysis of disease resistance genes: resistance to melon vine decline derived from Cucumis melo subsp. agrestis. Plant Breed. 119:329-334.

Iglesias A., B. Picó, and F. Nuez. 2000b. Pathogenicity of fungi associated with melon vine decline and selection strategies for breeding resistant cultivars. Ann. Appl. Biol. 137:141-151.

Jackson, L.E. 1995. Root architecture in cultivated and wild lettuce (Lactuca spp.). Plant Cell Environ. 18:885-894.

Leskovar, D.I. and P.J. Stofella. 1995. Vegetable seedling root systems: Morphology, development, and importance. HortScience 30:11531159.

Martyn, R.D., and M.E. Miller. 1996. Monosporascus root rot/ vine decline: An emerging disease of melon worldwide. Plant Dis. 80:716-725.

O'Toole, J.C. and W.L. Bland, 1987. Genotypic variation in crop plant root systems. Adv. Agron. 41:91-145.

Pantalone, V.R., G.J. Rebetzke, J.W. Burton, and T.E. Carter, Jr. 1996. Phenotypic evaluation of root traits in soybean and applicability to plant breeding. Crop Sci. 36:456-459.

Pivonia, S., R. Cohen, Y. Katan, I.S. Burger, Z. Ben Ze'ev, Karchi, and M. Edelstein. 1996. Sudden wilt of melons in southern Israel. Proc. V Eucarpia Meet. Cucurbits Genet. Breed. 285-290.

Wolff, D.W. and M. Miller. 1998. Tolerance to Monosporascus root rot and vine decline in melon (Cucumis melo L.) germplasm. HortScience 33:287-290.

Zobel, R.W. 1986. Rhizogenetics of vegetable crops. HortScience 21:956-959.

Zobel, R.W. 1995. Genetic control of root system, p. 21-31. In: Y. Waisel, A. Eshel, and U. Kafkafi (eds.). Plant roots. The hidden half. Marcel Dekker, New York 